\title{
Using the intervention mapping framework to develop, implement and evaluate effectiveness of a school based nutrition education program
}

\author{
P. Moitra ${ }^{1}$, P Verma ${ }^{2}$ and J. Madan ${ }^{3}$ \\ ${ }^{1}$ Department of Food, Nutrition \& Dietetics, Sir Vithaldas Thackersey College of Home Science (Autonomous), SNDT \\ Women's University, Santacruz West, Mumbai- 400049, India, \\ ${ }^{2}$ Department of Interdisciplinary Studies, SNDT Women's University, Juhu, Mumbai 400049, India and \\ ${ }^{3}$ Department of Food, Nutrition \& Dietetics, Sir Vithaldas Thackersey College of Home Science (Autonomous), SNDT \\ Women's University, Santacruz West, Mumbai- 400049, India
}

Unhealthy eating behaviours such as high consumption of energy-dense and nutrient poor foods and inadequate intakes of fruits and vegetables are common in children ${ }^{(1)}$. Nutrition education at schools is an effective strategy to enhance knowledge ${ }^{(2)}$, though efforts must also focus on fostering right attitudes and building skills and self- efficacy to modify dietary behaviours and improve healthy food consumption in children ${ }^{(3)}$.

We used the systematic approach of Intervention Mapping (IM), entailing six evidence based steps ${ }^{(4)}$ to guide the process of planning, implementing and evaluating the effectiveness of a 12 week multicomponent nutrition education program in improving nutritional knowledge, attitudes and healthy food consumption among 10-12 years old children in Mumbai, India.

The steps of IM were employed to conduct needs assessment, formulate behaviour change objectives, select underlying theory and inform the methods for developing and implementing the education program. Fourteen focus group discussions were conducted with children, parents and teachers to identify knowledge gaps and perceived barriers and the Health Belief Model was used to develop communication strategies and education materials. A school based pre post, randomized controlled study design evaluated the effectiveness of the program.

Children $(n=518)$, studying in grades 6 and 7 of four private and public schools were allocated to either experimental group (EG) or control group (CG) using school as a unit of cluster randomization. EG $(n=305)$ received 12 weeks of classroom based nutrition education (NE) and three parent education sessions; no sessions were conducted for CG $(\mathrm{n}=213)$. The impact of intervention was evaluated using a validated knowledge, attitude and practice (KAP) survey, administered at baseline, after 12 weeks and at 2 months follow up. The weekly frequencies of consumption of unhealthy snacks, fruits and vegetables were converted to daily equivalent servings and the intakes were averaged to derive total fruit, vegetable and unhealthy food consumption scores. Within-group and between- group changes were compared, significant at $\mathrm{p}<0.05$. Participants' ratings of instruction effectiveness were also noted.

The mean age of the participants was $11.2(1.1)$ years, $48 \%$ were girls and $49.6 \%$ attended public schools. EG reported improvements in mean knowledge $(39.3 \%)$, attitude $(7.3 \%)$ and practice $(9.6 \%)$ scores from pre to post intervention $(\mathrm{p}$ value $<0.001)$. No significant changes were observed in CG. Significant improvements in perceived benefits, barriers and self- efficacy scores, eating habits such as frequency of breakfast consumption and carrying healthy snacks to school and mean daily intakes of green leafy vegetables, chocolates and carbonated beverages were observed in EG.

A structured intervention mapping based nutrition education program can help understand the determinants of dietary behaviours, tailor the learning experiences to facilitate attitudinal changes and bring improvements in nutritional knowledge and practices related to healthy food consumption in children.

\section{Acknowledgments}

The authors would like to acknowledge the efforts of Dr J Sharma for his assistance with statistical analysis and the field research team, N Shah, T Chipkar, S Patil, and S Gaikwad for their hard work. Our appreciation is also due to the Principals of the institutes who provided permission to conduct the study and the homeroom/class teachers of grade 6 and grade 7 for their constant assistance. The authors acknowledge the valuable inputs and cooperation provided by the participants during the study.

\section{References}

1. Rathi N, Riddell L, Worsley A (2018) Br Food J.

2. Silveira JAC, Taddei JAAC, Guerra PH (2011) J Pediatr (Rio J),87(5):382-392.

3. Scherr RE, Linnell JD, Dharmar M, et al. (2017) J Nutr Educ Behav,49(5):368-379.

4. Fernandez ME, ten Hoor GA, van Lieshout S, et al. (2019) Front Public Heal.7(JUN):158. 